\title{
Cortona Colloquium: Strikes, Social Conflict, and World War I
}

\author{
Jane Bond-Howard
}

Lincoln University

An international colloquium, "Strikes, Social Conflict and World War I: Italy, France, Germany, Russia, Great Britain," was held at Cortona, Italy, from June 9 through June 13,1986. The primary sponsor of the colloquium was the Fondazione Giangiacomo Feltrinelli. Leopold Haimson of both the Harriman Institute of Columbia University and the Maison des Sciences de l'Homme, and Giulio Sapelli of the Fondazione Feltrinelli, opened the scholarly deliberations. Fifty people were in attendance, thirty of whom gave papers. Each participant spoke in his or her native language; simultaneous translation was provided. Because the papers had been submitted beforehand, each participant presented a fifteen-minute summary at the appropriate session. The summaries were followed by discussion.

Originally, sessions on the following topics had been planned: Comparative Studies; Strikes; Politics and Revolution; State Policy and Social Conflict; Territory and Industrial Sectors. However, once the colloquium was convened, it seemed more appropriate to organize the sessions around the five countries involved. The papers, nevertheless, reflected a concern with various aspects of the original topics.

Several major themes were examined by the colloquium. One issue about which the body could not agree was whether or not ald strikes are political in character. Some maintained that all strikes are political, whereas others maintained that some are purely economic. It was concluded that strikes are one of an arsenal of weapons that the claimants have available to them. The consequences of the claims can vary considerably from one circumstance to another. In many European countries, strikes have served as a warning, as a way of demonstrating that thousands support a particular cause.

Addressing the question of how strike statistics are to be assessed in terms of measuring unrest and protest, it was concluded that they are a product of interaction: in the long run, they represent the residue of what has not been agreed to through the bargaining process between capitalists, workers, and the managers of the state. Most strikes that could have happened did not happen because demands were dealt with in other ways. It was agreed that it is not possible to isolate strikes from the rest of the continuum of the other activities of 
workers. The worker in the factory cannot be isolated from the neighborhood that he or she comes out of - from his or her political and industrial culture.

There was disagreement about the universal applicability of models of continuity and discontinuity in industrial conflict. The Italian scholars noted that they do not use models of this nature. Those opposed to the use of these two models pointed out that in the West the enormous labor outburst at the end of World War I was a consequence of the unrest of the pre-war years with only an interruption and that in Russia there was continuity.

The colloquium participants agreed that in all the countries examined the working classes emerged at the end of the war much stronger than they had been at the beginning. This strength, depending upon differing conditions, manifested itself in various ways: in the form of mass influx into working-class organizations or trade unions; in the form of strike waves; or, as in England, in the form of the mass creation of a great labor party.

It was found that in some countries the great influx of workers into defense industries created a situation in which this expanded work force escaped the control of the pre-war trade unions. Where this occurred-often in France and Germany-the strike movements took place outside the control of the traditional unions. In Italy, on the other hand, strike waves were preceeded by a surge in trade-union membership; indeed, for the first time, workers joined trade unions en masse.

The colloquium also examined the role of the state. An attempted increase of the role of the state, as it tried to fully harness national economic resources for the war effort, was discerned. In most but not all countries, this attempt seems to have been successful. The repressive role that the state often played was also noted.

There was agreement that the need to mobilize on a unique and unprecedented scale had political and economic consequences for all the countries concerned. All the governments promised their people something in return for fighting the war: permanent peace, democracy, housing, a better life. These promises raised expectations and became a part of the political debate after the war.

Another important point that emerged from the papers was the vanguard role in the strike movements played by the metal workers, particularly those working for national defense. Even though many of these strikes failed, workers in the metal processing industry came to provide the working-class base of the new Communist parties that emerged in Europe just after World War I.

The phenomenon of vast numbers of women coming into the work force as a result of war mobilization was commented upon, as was their often militant behavior. It was noted that these developments certainly contributed to women's obtaining the vote in many places.

Although no serious political crisis occurred in any of the victorious countries after the war, the feeling was that there were certain zones in Europe 
where revolution could not happen, even if defeat had been suffered. France, Great Britain, the Benelux countries, Scandinavia, and Germany were such zones. In Germany, with the possible exception of Saxony, defeat created conditions that only looked revolutionary. In a second zone-Italy, the Balkans, the Ukraine-social tensions were such that powers collapsed and revolution broke out in some of these areas. Then, there was the third zone, comprised within the Hapsburg Empire, where the political regime disintegrated. The absence of papers covering this area was unfortunate. What emerged from this area-by-area analysis was that there was clearly no revolutionary situation in Western Europe between 1918 and 1920.

The participating scholars found both the papers and the exchange of information and ideas most helpful to their research. All agreed that the proceedings of the colloquium, when published, will provide a rich contribution to the knowledge of Europe during and after World War I. 